\title{
Ratio of crown-rump distance to total length in preterm and term infants
}

\author{
PAUL MERLOB, YAKOV SIVAN, AND SALOMON H REISNER \\ From the Department of Neonatalogy, Beilinson Medical Centre, Petah Tikva, and the Tel Aviv University \\ Sackler School of Medicine, Tel Aviv, Israel.
}

SUMMARY The known measurements for the determination of body proportions cannot be used practically in the neonate. The ratio of crown-rump distance to total length appears the most useful index for objective evaluation of disorders that influence body proportions in the neonate. Normal standards for this ratio in newborn infants from 27 to 41 weeks' gestation are presented in relation to gestational age and birth weight.

The presence of a growth abnormality in the newborn infant may be detected by measuring the crown-heel length or by using Rohrer's ponderal index. ${ }^{1}$ However, this may be misleading as some disorders selectively affect the growth of the trunk or extremities. It is therefore helpful to know whether the infant's body proportions are normal or whether there is any disproportion between his segmental measurements.

In the older child anomalies of body proportion can usually be confined to measuring the upper to lower segment ratio, the sitting height for stature, ${ }^{23}$ or the AF/AT ratio ${ }^{4}$ (the ratio between the distance from the anterior superior iliac spine to the tip of the middle finger with the arm fully extended on the thigh (AF) and the distance from the anterior superior iliac spine to the tibial tuberosity (AT)). Since it is not practically possible to do these measurements in the newborn period, we use the ratio crown-rump distance to length as an alternative measurement to confirm quantitatively the clinical impression of abnormal body proportions in the newborn infant.

The present study was undertaken in order to establish normal standards for the ratio of crownrump distance to length in newborn infants from 27 to 41 weeks' gestation in relation to gestational age and birth weight.

\section{Material and methods}

The ratio of crown-rump distance to length was measured in 87 term (48 male and 39 female) and 111 preterm (55 male and 56 female) infants

Received for publication 27 Fcbruary 1985.

Accepted for publication 3 April 1985. between gestational ages of 27 and 41 weeks. The details of this group of infants have previously been published. $^{5}$

All measurements were made between 36 and 60 hours of age by two physicians using a neonatometer (Infa-Length, Olympic Surgical Company). The total length was measured from the crown of the head to the heel with the foot kept at an angle of $90^{\circ}$. One physician held the infant's head gently against the head end of the neonatometer. With one hand the infant's head was rotated in order to elicit the tonic neck reflex resulting in straightening of the leg at the hip and knee. With the other hand the infant's shoulders were held down. The other physician held the fully extended right leg with the foot in a vertical position. The foot board was moved up until it touched the sole of the foot in its entire length. The total length (crown-heel) was read off from a scale on the side of the neonatometer to the closest millimetre.

The crown-rump distance was defined as the distance from the crown of the head to the lowest part of the trunk which corresponds to either the perineum or the lowest surface of the buttock. ${ }^{6}$ One physician held the infant's head gently against the head end of the neonatometer with the lowest rim of the orbit in the same vertical plane as the auditory canal. He also held the infant's shoulders down with his index fingers. The other physician held the 0 infant's legs flexed with a popliteal angle of $90^{\circ}$ while holding the pelvis down and immobile. The foot board was moved up until it touched the infant's perineum. The crown-rump distance was then read off directly from the scale on the side of the neonatometer to the closest millimetre. The crownrump distance to length ratio was then calculated. 


\section{Results}

No statistical difference was found between boys and girls so the combined mean \pm 2 SD was used. The results of crown-rump distance and crown-rump distance to total length ratio at various gestational ages are given in the table. The distribution of values for crown-rump distance approximates a Gaussian curve. Normal values (mean \pm 2 SD) for this measurement are depicted in fig 1 . The ratio of crown-rump distance to total length is fairly constant during intrauterine growth $(0 \cdot 665 \pm 0 \cdot 027)$ (fig 2 , table).

Since gestational age cannot always be accurately determined, and intrauterine growth retardation is characteristic of many congenital syndromes, the results are evaluated also in relation to birth weight. For the determination of standard values in relation to birth weight the infants were divided into $250 \mathrm{~g}$ groups (751 to $1000 \mathrm{~g}, 1001$ to $1250 \mathrm{~g}$, etc). These

TABLE Crown-rump distance and ratio of crown-rump to total length at various gestational ages.

\begin{tabular}{|c|c|c|c|c|}
\hline \multirow[t]{2}{*}{$\begin{array}{l}\text { Gestational } \\
\text { age }(w k)\end{array}$} & \multicolumn{2}{|c|}{$\begin{array}{l}\text { Crown-rump distance } \\
(\mathrm{cm})\end{array}$} & \multicolumn{2}{|c|}{ Crown-rump/length } \\
\hline & Mean & $\pm 2 S D$ & Mean & $\pm 2 S D$ \\
\hline 27 & $23 \cdot 19$ & 1.52 & $0 \cdot 653$ & 0.038 \\
\hline 28 & $23 \cdot 82$ & $2 \cdot 14$ & 0.656 & 0.0136 \\
\hline 29 & $24 \cdot 69$ & $2 \cdot 36$ & 0.659 & 0.034 \\
\hline 30 & $25 \cdot 70$ & $2 \cdot 34$ & 0.663 & $(0 \cdot 0) 32$ \\
\hline 31 & $26 \cdot 65$ & $2 \cdot 28$ & 0.664 & $0 \cdot(030)$ \\
\hline 32 & $27 \cdot 62$ & $2 \cdot 18$ & 0.665 & 0.032 \\
\hline 33 & $28 \cdot 61$ & $2 \cdot 34$ & $0 \cdot 666$ & 0.028 \\
\hline 34 & $29 \cdot 52$ & $2 \cdot 38$ & 0.667 & 0.028 \\
\hline 35 & $30 \cdot 27$ & $2 \cdot 30$ & 0.667 & 0.028 \\
\hline 36 & $31 \cdot 02$ & $2 \cdot 12$ & 0.669 & 0.032 \\
\hline 37 & $31 \cdot 86$ & 1.96 & 0.670 & 0.030 \\
\hline 38 & $32 \cdot 64$ & 1.98 & 0.672 & $0 \cdot(030$ \\
\hline 39 & $33 \cdot 22$ & $2 \cdot 02$ & 0.673 & 0.030 \\
\hline 40 & $33 \cdot 56$ & $2 \cdot 14$ & 0.673 & 0.030 \\
\hline 41 & $33 \cdot 71$ & $2 \cdot 16$ & 0.673 & 0.028 \\
\hline
\end{tabular}

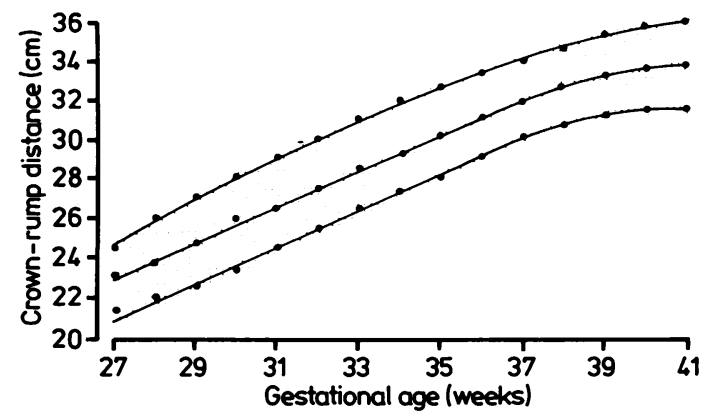

FIG 1 Curve values of crown-rump distance. The points represent the mean value $\pm 2 S D$ for each age group.

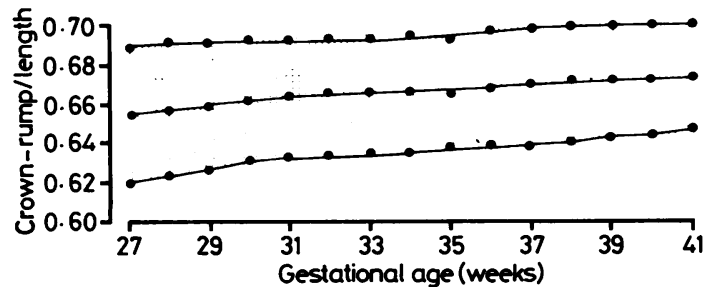

FIG 2 Curve values of ratio of crown-rump distance to total length. The points represent the mean value $\pm 2 S D$ for each age group.

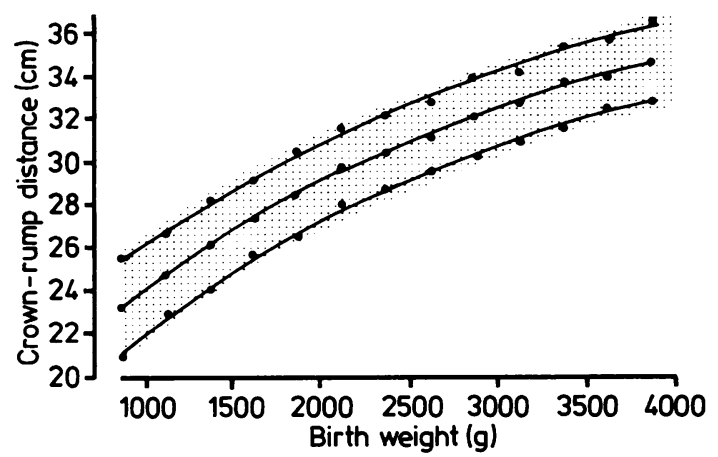

FIG 3 Curve values of crown-rump distance (mean $\pm S D$ ) in relation to birth weight (infants divided into $250 \mathrm{~g}$ groups).

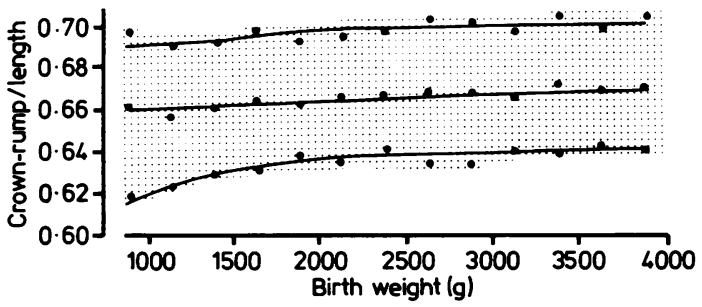

FIG 4 Curve values of ratio of crown-rump distance to total length (mean $\pm 2 S D$ ) in relation to birth weight (infants divided into $250 \mathrm{~g}$ groups).

results are presented in figs 3 and 4 . The constancy of the ratio of crown-rump distance to total length during intrauterine growth is also evident when birth weight is taken into account.

\section{Discussion}

The known measurements for the determination of 
body proportions in children (upper to lower segment ratio, the sitting height for stature, ${ }^{23}$ and AF/AT ratio ${ }^{4}$ ) are difficult measurements to obtain accurately and easily, especially in the neonatal period. ${ }^{7}$ The crown-rump distance is also a relatively difficult parameter, but it can be obtained accurately in the neonatal period with good technique and training. The varying thickness of the adiposemuscular layer of the buttocks in neonates does not create errors in estimation, if the precaution is taken of bringing the foot board of the neonatometer gently up to the infant's perineum.

For these reasons, the ratio of crown-rump distance to total length appears to be a useful index, or at least one that is as reliable as any, for the objective determination of body proportions in the neonatal period, and should be useful in the evaluation and follow up of disorders that influence body proportions. It is of importance particularly in the evaluation of the disproportionate short stature of the neonatal skeletal dysplasias. According to the results obtained, an infant with a short trunk will have a low index, while in a neonate with short limbs the index will be increased.

\section{References}

1 Miller HC, Hassanein K. Diagnosis of impaired fetal growth in newborn infants. Pediatrics 1971:48:511-22.

2 McKusick VA. Heritable disorders of connective tissue. 4th ed. St Louis: Mosby, 1972:70.

3 Tanner JM. Physical growth and development. In: Forfar JO, Arneil SC, eds. Textbook of paediatrics. 1st ed. Edinburgh: Churchill Livingstone, 1973:257.

4 Buyse M. Feingold M. Growth abnormalities in genetic syndromes. Postgrad Med J 1977;62:67-77.

5 Sivan Y, Merlob P. Reisner SH. Philtrum length and intercommissural distance in newborn infants. $J$ Med Genet 1983;20: 130-1.

- Feingold M. Guidelines for clinical measurements. In: Bergsma D, ed. Syndrome identification. Vol 3. New York: The National Foundation-March of Dimes, 1975:4.

7 Smith DW. Growth and its disorders. 1st ed. Philadelphia: Saunders, 1977:18.

Correspondence and requests for reprints to Dr Paul Merlob, Department of Neonatology, Beilinson Medical Center, Petah Tikva 49151, Israel. 